\title{
The polyAT, intronic IVSI I-6 and Lys939GIn XPC polymorphisms are not associated with transitional cell carcinoma of the bladder
}

\author{
SC Sak', JH Barrett' ${ }^{2}$ AB Paul ${ }^{3}$, DT Bishop ${ }^{2}$ and AE Kiltie*,I \\ 'Molecular Radiobiology Group, Cancer Research UK Clinical Centre in Leeds, St James's University Hospital, Leeds LS9 7TF, UK; ' ${ }^{2}$ Genetic Epidemiology \\ Division, Cancer Research UK Clinical Centre in Leeds, St James's University Hospital, Leeds LS9 7TF, UK; ${ }^{3}$ Department of Urology, St James's University \\ Hospital, Leeds LS9 7TF, UK
}

Chemical carcinogens from cigarette smoking and occupational exposure are risk factors for bladder transitional cell carcinoma (TCC). The Xeroderma Pigmentosum Group C (XPC) gene is essential for repair of bulky adducts from carcinogens. The Xeroderma Pigmentosum Group C gene polymorphisms may alter DNA repair capacity (DRC), thus giving rise to genetic predisposition to bladder cancer. Recent studies have demonstrated linkage disequilibrium between three polymorphisms in the XPC gene (polyAT, IVSI I-6 and Lys939GIn) and these have been shown to influence the DRC, as well as to be associated with bladder cancer risk. We analysed all three XPC polymorphisms in 547 bladder TCC patients and 579 cancer-free controls to investigate the association between these polymorphisms and bladder cancer susceptibility, and we also attempted to assess gene-environmental interactions. We confirmed strong linkage disequilibrium among the polymorphisms (Lewontin's $D^{\prime}>0.99$ ). Using logistic regression adjusting for smoking, occupational and family history, neither the heterozygote nor the homozygote variants of these polymorphisms were associated with increased bladder cancer risk (adjusted odds ratio [95\% confidence interval] for heterozygote 0.82 [0.63-1.07], 0.82 $[0.63-1.08]$ and $0.83[0.63-1.08]$ for PolyAT, IVSI I-6 and Lys939 GIn, respectively and homozygote variant, 0.98 [0.68-1.42], 0.99 $[0.69-1.43]$ and 1.01 [0.70-1.46]). Moreover, we did not find any significant interaction between these XPC polymorphisms and environmental exposure to cigarette smoking and occupational carcinogens.

British Journal of Cancer (2005) 92, 2262-2265. doi: 10.1038/sj.bjc.66026I6 www.bjcancer.com

Published online 10 May 2005

(C) 2005 Cancer Research UK

Keywords: bladder cancer; transitional cell carcinoma; Xeroderma Pigmentosum Group C (XPC); polymorphisms

Transitional cell carcinoma (TCC) of the bladder is the fourth commonest cancer in men and eighth in women in the USA and UK (Greenlee et al, 2000; Office of National Statistics, 2000). The two established risk factors for TCC are chemical carcinogens from cigarette smoking and occupation exposure (Zeegers et al, 2000; Kogevinas et al, 2003). Bulky DNA adducts formed by these carcinogens are repaired by nucleotide excision repair (NER). Failure to repair this DNA damage can cause mutations in oncogenes and tumour suppressor genes resulting in tumour formation. The xeroderma pigmentosum group $\mathrm{C}(\mathrm{XPC})$ protein plays an important role in the initiation of this pathway. Polymorphisms in the XPC gene may alter NER capacity, thus giving rise to genetic predisposition to bladder cancer.

Recently, Khan et al (2000) discovered a common XPC polyAT (XPC-PAT) polymorphism in intron 9 , which involves deletion of five base pairs (bp) and insertion of an $83 \mathrm{bp}$ AT repeat. The XPCPAT was found to be in strong linkage disequilibrium (LD) with the XPC coding single-nucleotide polymorphism (SNP) Lys939Gln in exon 15 and also an intronic SNP (IVS11-6) in intron 11 that effects alternative splicing and hence alters protein function (Khan et al, 2002). Although the abnormal splice variant resulted in

*Correspondence: Dr AE Kiltie; E-mail: anne.kiltie@cancer.org.uk Received 25 January 2005; revised 6 April 2005; accepted 6 April 2005; published online 10 May 2005 reduced DNA repair capacity (DRC) in vitro using an allelespecific post-UV plasmid host cell reactivation assay (Khan et al, 2002), the variant XPC 939Gln allele was not associated with reduced DRC (Khan et al, 2000). However, in a recent casecontrol study, homozygotes for the 939Gln allele were found to have a significantly increased risk of bladder cancer (Sanyal et al, 2004). In addition, the homozygous variant XPC-PAT insertion $($ ' $+I+$ ') has been associated with an increased risk of squamous cell carcinoma of the head and neck (Shen et al, 2001), and in lymphocytes from normal subjects homozygotes for XPC-PAT had reduced DRC (Qiao et al, 2002).

We therefore hypothesised that the XPC polymorphisms XPCPAT, IVS11-6 and Lys939Gln have a role in the aetiology of TCC of the bladder through modification of risk produced by smoking and occupational exposure. We conducted a case-control study to examine the LD between all three polymorphisms and their association with bladder TCC risk. We also investigated geneenvironment interactions between the XPC polymorphisms and smoking and occupational exposure to chemical carcinogens.

\section{MATERIALS AND METHODS}

\section{Study population}

Local ethical approval was obtained from the Leeds Teaching Hospitals Local Research Ethics Committee (LREC) for this study. 
Written informed consent was obtained from all of the participating subjects.

In total, 626 patients were admitted to our institution for bladder tumour surgery between August 2002 to April 2004. Eligibility criteria for cases were patients with pathologically confirmed TCC in the tumour specimen obtained from biopsy or surgical resection, age more than 18 years and mental competence to give informed consent. Exclusion criteria were patients with non-TCC tumours $(n=46)$, mental incompetence such as dementia $(n=6)$, patients who had had a blood transfusion less than 1 month before surgery $(n=23)$. In all, $92 \%$ of eligible patients were recruited (547 patients out of 549 eligible subjects); only two patients declined to participate in this study. Controls were subjects who were cancer free and had no symptom of haematuria (blood in urine). They were frequency matched by age and sex but no attempt was made at one-to-one matching of cases and controls. The controls $(n=579)$ were recruited from two sources: community-based $(n=227)$ from a previous molecular epidemiology study (Barrett et al, 2003), in the same region and hospitalbased $(n=352)$ from individuals who attended the ophthalmology and otolaryngology clinics in the same institution. Overall, the refusal rate of participation from the controls was approximately $20 \%$. After informed consent was obtained, a blood specimen was collected from each subject.

\section{Data collection}

Each subject underwent a 15-20 min interview with investigators and completed a structured health questionnaire regarding smoking, occupation and family history. Smoking status was recorded as nonsmoker, exsmoker or current smoker, and smoking dose was measured in pack years. (One pack-year was defined as smoking 20 cigarettes per day for 1 year or any pattern leading to the same total exposure). Occupational exposure was defined as participating in occupations involving the rubber industry, the plastics industry, laboratories, printing, paints, dyes or diesel fumes. Positive family history was defined as reporting having any first- or second-degree relative diagnosed with bladder cancer. Histopathological information regarding tumour stage and grade was determined according to the TNM (tumour-nodesmetastasis) staging system and data were obtained from patient medical notes and the hospital pathology report.

\section{Genotyping}

Genomic DNA was extracted from blood samples collected from patients with TCC and control subjects using the modified salt precipitation method Puregene kit (Nottingham, UK) in the Regional Genetics Laboratory, Leeds. The method of Khan et al (2000) was used to amplify the XPC polyAT polymorphism. We fluorescently labelled the forward primer used by Khan et al to allow gel-free genotyping using a Genetic Analyser 3100 (Applied Biosystems, Foster City, CA, USA). Genotyping for SNP Lys939Gln and IVS11-6 were performed in the Cancer Research UK Genotyping Facility, Oxford, using the allelic discrimination $5^{\prime}$ nuclease assay (Taqman) without prior knowledge of the subject's clinical status. Primer and probe sets were designed and manufactured using Applied Biosystems 'Assay-by-Design' custom service (Applera, Austria). The primers and probe sets used for Lys939Gln were: forwards primer ( $5^{\prime}$ AGCAGCTTCCCAC CTGTTC $\left.3^{\prime}\right)$, reverse primer $\left(5^{\prime}\right.$ GTGGGTGCCCCTCTAGTG $\left.3^{\prime}\right)$, VIC probe $\left(5^{\prime}\right.$ CTCACAGCTTCTCAAAT $\left.3^{\prime}\right)$ and FAM probe $\left(5^{\prime}\right.$ CACAGCTGCTCAAAT $3^{\prime}$ ), and for IVS11-6 were forward primer $\left(5^{\prime}\right.$ GAGGTACACATTCCCAAACTCGTT $\left.3^{\prime}\right)$, reverse primer $\left(5^{\prime}\right.$ GCTGGCCAAATGCTGACTTG $3^{\prime}$ ), VIC probe (5' CACCCGCCA CAGGT $\left.3^{\prime}\right)$ and FAM probe (5' TCACCCGACACAGGT $\left.3^{\prime}\right)$. Each PCR reaction was carried out in a 384-well MicroAmp optical plate (ABI) using a total volume of $10 \mu \mathrm{l}$ containing $5 \mu \mathrm{l}$ of $2 \times$ Taqman universal master mix, $20 \mu \mathrm{M}$ of sequence detection primers, $5 \mu \mathrm{m}$ of allele-specific hybridisation probes and $10 \mathrm{ng}$ of genomic DNA. Thermal cycling parameters were: $2 \mathrm{~min}$ at $50^{\circ}$ and $10 \mathrm{~min}$ at $95^{\circ}$ for primary denaturation, followed by 40 cycles of $15 \mathrm{~s}$ at $95^{\circ}$ and $1 \mathrm{~min}$ at $60^{\circ}$. Once the thermal cycling had been completed, the plate was transferred to an Applied Biosystems 7900HT sequence detection system and the fluorescence in each reaction was read. Using the graphical view within the SDS software (ABI), each group of alleles could be manually selected and each sample designated as homozygous wild-type, heterozygous or homozygous variant. As a quality control, $5 \%$ of the samples $(n=57)$ were reanalysed, and results were identical for all samples $(100 \%$ concordance).

\section{Statistical analysis}

All data were analysed using STATA version 8 (StataCorp LP, Texas). Hardy-Weinberg equilibrium analyses were performed to compare observed and expected genotype frequencies using a chisquared goodness-of-fit test. The LD between polymorphisms was estimated by pairwise Lewontin's $D^{\prime}$ using the STATA pwld function ( $\langle$ http://www-gene.cimr.cam.ac.uk/clayton/ $\rangle$ ). The odds ratio (OR) and $95 \%$ confidence interval (CI) for bladder cancer associated with each genotype were calculated using logistic regression analysis and were adjusted for established bladder

Table I Characteristics of study subjects

\begin{tabular}{|c|c|c|c|}
\hline Risk factors & Cases (\%) & Controls (\%) & $P$-value* \\
\hline \multicolumn{4}{|c|}{ Age at interview (years) } \\
\hline$\leqslant 60$ & $54(13.0)$ & $75(9.9)$ & \\
\hline $61-70$ & $142(24.3)$ & $|4|(26.0)$ & \\
\hline $71-80$ & $212(39.0)$ & $226(38.7)$ & \\
\hline$\geqslant 80$ & $139(23.7)$ & $137(25.4)$ & 0.4 \\
\hline \multicolumn{4}{|l|}{ Gender } \\
\hline Female & $159(29.1)$ & $200(34.5)$ & \\
\hline Male & $388(70.9)$ & $379(65.5)$ & 0.05 \\
\hline \multicolumn{4}{|l|}{ Race } \\
\hline White & $539(98.5)$ & $57 \mid(98.6)$ & \\
\hline Other & $8(1.5)$ & $8(1.4)$ & 0.91 \\
\hline \multicolumn{4}{|l|}{ Smoking status ${ }^{\mathrm{a}}$} \\
\hline Never & $121(22.2)$ & $195(33.7)$ & \\
\hline Ex & $293(53.7)$ & $288(49.7)$ & \\
\hline Current & $132(24.1)$ & $96(16.6)$ & $<0.001$ \\
\hline \multicolumn{4}{|c|}{ Number of years smoked ${ }^{\mathrm{a}}$} \\
\hline 0 & $121(22.2)$ & $195(33.7)$ & \\
\hline $1-20$ & $81(\mid 4.8)$ & $108(18.6)$ & \\
\hline $21-40$ & $136(24.9)$ & $132(22.8)$ & \\
\hline$>40$ & $208(38.1)$ & $144(24.9)$ & $<0.001$ \\
\hline \multicolumn{4}{|c|}{ Number of pack-years ${ }^{a}$} \\
\hline 0 & $121(22.2)$ & $195(33.7)$ & \\
\hline$\leqslant 25.5$ & $195(35.7)$ & $202(34.9)$ & \\
\hline$>25.5$ & $216(39.6)$ & $176(30.4)$ & \\
\hline Pipe smoker & $14(2.5)$ & $6(1.0)$ & $<0.001$ \\
\hline \multicolumn{4}{|c|}{ Occupational exposure } \\
\hline No & $397(72.6)$ & $482(83.2)$ & \\
\hline Yes & $150(27.4)$ & $97(16.8)$ & $<0.001$ \\
\hline \multicolumn{4}{|c|}{ Family history of bladder cancer } \\
\hline No & $521(95.2)$ & $566(97.8)$ & \\
\hline Yes & $26(4.8)$ & $13(2.2)$ & 0.02 \\
\hline
\end{tabular}

*All P-values were calculated by chi-squared testing of contingency tables. ${ }^{\mathrm{a}}$ One case had inadequate smoking information. 
cancer risk factors (age, sex, cigarette smoking, occupational exposure and family history).

\section{RESULTS}

\section{Subject characteristics}

The demographic characteristics of the 547 cases and 579 controls are shown in Table 1. The majority of the subjects (98.6\%) were Caucasian and $83.5 \%$ were born in the Yorkshire region, UK. Despite attempts to match on sex, there were slightly more men in the case group (71\%) than the control group (65\%). As expected, the smoking prevalence among cases was higher than in controls. Similarly, cases were more likely to have had occupational exposure and a positive family history of bladder cancer compared to controls $(P<0.001$ and 0.02 , respectively).

\section{XPC polymorphisms and the risk of bladder TCC}

Overall, genotyping was successful in more than $98 \%$ of samples (99.6, 97.9 and $97.1 \%$ for XPC-PAT, IVS11-6 and Lys939Gln, respectively). The control genotype distribution for all three polymorphisms was in Hardy-Weinberg equilibrium $(P=0.76$, 0.63 and 0.67 for XPC-PAT, IVS11-6 and Lys939Gln, respectively). We also compared the genotype distributions between the community and the hospital controls and found no significant difference in genotype distribution between the two control groups $(P=0.18,0.13,0.12$ for XPC-PAT, IVS11-6 and Lys939Gln, respectively). Therefore, we combined the controls to increase

Table 2 The association between XPC-PAT, IVSII-6 and Lys939GIn among 1086 subjects

\begin{tabular}{lrrrr}
\hline & \multicolumn{3}{c}{ IVS II-6 } & \\
\cline { 2 - 4 } XPC-PAT & C/C & C/A & A/A & Lys939GIn \\
\hline$-1-$ & 394 & 0 & 0 & $\mathrm{~A} / \mathrm{A}$ \\
& 0 & 3 & 0 & $\mathrm{~A} / \mathrm{C}$ \\
& 0 & 0 & 0 & $\mathrm{C} / \mathrm{C}$ \\
$-1+$ & 0 & 0 & 0 & $\mathrm{~A} / \mathrm{A}$ \\
& 1 & $5 / 7$ & 0 & $\mathrm{~A} / \mathrm{C}$ \\
$+1+$ & 0 & 0 & 1 & $\mathrm{C} / \mathrm{C}$ \\
& 0 & 0 & 0 & $\mathrm{~A} / \mathrm{A}$ \\
& 0 & 1 & 0 & $\mathrm{~A} / \mathrm{C}$ \\
& 0 & 0 & 169 & $\mathrm{C} / \mathrm{C}$ \\
\hline
\end{tabular}

our power to detect an association between the polymorphisms and bladder TCC risk. Among 1086 subjects with complete genotypes for all three polymorphisms, the genotype distribution and LD are shown in Table 2. The pairwise Lewontin's $D^{\prime}$ among the three polymorphisms were all at least 0.99 .

The frequencies of the XPC-PAT, IVS11-6 and Lys939Gln in bladder TCC cases and the controls are shown in Table 3. To evaluate the risk of bladder TCC according to genotype, logistic regression analysis was conducted with an adjustment for age, gender, smoking, occupation and family history of bladder cancer (Table 3). There was no association between any of the three polymorphisms and bladder TCC risk. We also analysed the association of these polymorphisms in white subjects only, and the result was very similar. None of the three polymorphisms were significantly associated with increased bladder TCC risk (chi square, $P=0.14,0.17,0.17$ for XPC-PAT, IVS11-6 and Lys939Gln, respectively). We also found no evidence of interactions between the genotypes of any of the three polymorphisms and smoking exposure or occupational exposure ( $P$-value for departure from multiplicative joint effect $=0.75$ and 0.82 for smoking and occupational exposure). We present data for XPC-PAT only as results for the other two polymorphisms were very similar (Table 4 and data not shown).

\section{DISCUSSION}

To our knowledge, this is the largest case-control study of all three polymorphisms of the XPC gene in bladder cancer, and it involved an ethnically homogeneous population. With a sample size of 547 cases and 579 controls, we had an $83 \%$ power (twosided test, $P=0.05$ ) to detect an OR of 1.6 for the homozygote variant compared with other genotypes. Our study was limited by potential selection bias since we included both community and hospital controls. However, the similarity of the genotype distributions between the two control groups makes it unlikely that the use of controls initially recruited for another study has influenced our conclusions. We also cannot exclude any recall bias for smoking and occupational exposure.

From our data, we observed no association between the three XPC polymorphisms and bladder TCC risk. Sanyal et al, in a study of 304 cases and 246 controls, estimated an OR of 1.97 (95\% CI $1.10-3.57$ ) for $939 \mathrm{Gln} / \mathrm{Gln}$ homozygotes compared with those with other genotypes. Although our study was larger and had sufficient power to replicate this, we found no evidence to support the finding of increased bladder cancer risk. This discrepancy could be due to differences in the populations studied. Alternatively, the earlier finding could be a false positive result. Wacholder et al (2004) have shown that, unless the prior probability of an

Table 3 The association between the XPC polymorphisms (XPC-PAT, Lys939Gln and IVSI I-6) and bladder TCC risk

\begin{tabular}{|c|c|c|c|c|c|c|}
\hline Polymorphisms & Genotypes & Control $^{\mathrm{a}}(n)$ & $\operatorname{Cases}^{\mathrm{a}}(n)$ & Crude OR $(95 \% \mathrm{Cl})$ & Adjusted OR $(95 \% \mathrm{Cl})$ & $P$-value \\
\hline & $+1-$ & 288 & 242 & $0.80(0.62-1.03)$ & $0.82(0.63-1.07)$ & 0.15 \\
\hline \multirow[t]{3}{*}{ Lys939GIn } & A/A & 192 & 204 & 1.00 & 1.00 & \\
\hline & $\mathrm{A} / \mathrm{C}$ & 285 & 241 & $0.80(0.61-1.04)$ & $0.82(0.63-1.08)$ & 0.14 \\
\hline & $\mathrm{C} / \mathrm{C}$ & 84 & 87 & $0.97(0.67-1.42)$ & $0.99(0.69-1.43)$ & 0.97 \\
\hline & $\mathrm{A} / \mathrm{C}$ & 287 & 243 & $0.81(0.62-1.04)$ & $0.83(0.63-1.08)$ & 0.16 \\
\hline & A/A & 83 & 87 & $1.00(0.70-1.43)$ & $1.01(0.70-1.46)$ & 0.96 \\
\hline
\end{tabular}

Adjusted OR: odds ratio adjusted for age, sex, smoking, occupational exposure and family history of bladder cancer, $95 \% \mathrm{Cl}=95 \%$ confidence interval. ${ }^{\text {TT }}$ The total number of cases and controls vary between polymorphisms because of failure of genotyping. 
Table 4 Stratified analysis of XPC polymorphisms (XPC-PAT) and bladder TCC risk by smoking status and occupational exposure

\begin{tabular}{|c|c|c|c|c|c|c|}
\hline XPC-PAT & Genotypes & Control (n) & Cases $^{a}(n)$ & Crude OR $(95 \% \mathrm{Cl})$ & bOR (95\% Cl) & $P$-value \\
\hline Nonsmoker & $-1-$ & 64 & 46 & 1.00 & 1.00 & \\
\hline Ex and current smoker & $-1-$ & 140 & 168 & 1.00 & 1.00 & \\
\hline & $+1-$ & 183 & 187 & $0.85(0.63-1.15)$ & $0.87(0.64-1.18)$ & 0.38 \\
\hline & $+/+$ & 59 & 67 & $0.95(0.63-1.43)$ & $0.96(0.63-1.46)$ & 0.84 \\
\hline \multicolumn{7}{|l|}{ Occupational exposure } \\
\hline \multirow[t]{3}{*}{ No } & $-1-$ & 169 & $|5|$ & 1.00 & 1.00 & \\
\hline & $+1-$ & 243 & 180 & $0.83(0.62-1.11)$ & $0.82(0.61-1.11)$ & 0.21 \\
\hline & $+/+$ & 69 & 64 & $1.04(0.69-1.56)$ & $1.08(0.7 \mid-1.63)$ & 0.73 \\
\hline \multirow[t]{3}{*}{ Yes } & $-1-$ & 35 & 64 & 1.00 & 1.00 & \\
\hline & $+1-$ & 45 & 62 & $0.75(0.43-1.32)$ & $0.72(0.40-1.27)$ & 0.25 \\
\hline & $+1+$ & 16 & 23 & $0.79(0.37-1.68)$ & $0.76(0.35-1.65)$ & 0.49 \\
\hline
\end{tabular}

One case was excluded because of missing data on smoking status. ${ }^{b} \mathrm{OR}=$ odds ratio adjusted for age, sex, occupational exposure and family history of bladder cancer (smoking status); $\mathrm{OR}=$ odds ratio adjusted for age, sex, smoking status and family history of bladder cancer (occupational exposure). $95 \% \mathrm{Cl}=95 \%$ confidence interval.

association is high, a large proportion of genetic associations showing marginal statistical significance in studies of low to moderate power will be false positive results. Of interest, a recent follow-up study of 288 superficial bladder cancer patients showed no association between XPC-PAT or Lys939Gln variants and increased risk of tumour recurrence ( $\mathrm{Gu}$ et al, 2005).

We observed no interactions between the three XPC polymorphisms and smoking or occupational exposure by stratifying by smoking status (nonsmokers vs ex or current smokers) and by occupational exposure (yes or no). However, our study is unable to rule out more complex interactions with environmental exposures.

\section{REFERENCES}

Barrett JH, Smith G, Waxman R, Gooderham N, Lightfoot T, Garner RC, Augustsson K, Wolf CR, Bishop DT, Forman D, Colorectal Cancer Study Group (2003) Investigation of interaction between $N$-acetyltransferase 2 and heterocyclic amines as potential risk factors for colorectal cancer. Carcinogenesis 24: 275-282

Greenlee RT, Murray T, Bolden S, Wingo PA (2000) Cancer Statistics. CA Cancer J Clin 50: 7-33

Gu J, Shao H, Dinney CP, Zhu Y, Leibovici D, Bermejo CE, Grossman HB, $\mathrm{Wu} \mathrm{X}$ (2005) Nucleotide excision repair gene polymorphisms and recurrence after treatment for superficial bladder cancer. Clin Cancer Res 11: $1408-1415$

Khan SG, Metter EJ, Tarone RE, Bohr VA, Grossman L, Hedayati M, Bale SJ, Emmert S, Kraemer KH (2000) A new xeroderma pigmentosum group C poly(AT) insertion/deletion polymorphism. Carcinogenesis 21: 1821-1825

Khan SG, Muniz-Medina V, Shahlavi T, Baker CC, Inui H, Ueda T, Emmert S, Schneider TD, Kraemer KH (2002) The human XPC DNA repair gene: arrangement, splice site information content and influence of a single nucleotide polymorphism in a splice acceptor site on alternative splicing and function. Nucleic Acids Res 30: 3624-3631

Kogevinas M, 't Mannetje A, Cordier S, Ranft U, Gonzalez CA, Vineis P, Chang-Claude J, Lynge E, Wahrendorf J, Tzonou A, Jockel KH, Serra C, Porru S, Hours M, Greiser E, Boffetta P (2003) Occupation and bladder cancer among men in Western Europe. Cancer Causes Control 14: 907-914
In conclusion, we found the XPC polymorphisms XPC-PAT, Lys939Gln and IVS11-6 to be in LD $\left(D^{\prime} \geqslant 0.99\right)$, and none of the polymorphisms was associated with increased risk of bladder TCC.

\section{ACKNOWLEDGEMENTS}

We thank Jo Robinson for help with blood collection, and Dr Juliette Randerson-Moor and Dr Mark Harland for assistance with genotyping. We thank Mr G Kelly and Mr T Dabbs for allowing us to approach their patients for use as control subjects. This work was funded by Yorkshire Cancer Research and Cancer Research UK.

Office of National Statistics (2000) Office of National Statistics Cancer Statistics registrations. MB1 31. Available from http://www.statistics.gov.uk

Qiao Y, Spitz MR, Guo Z, Hadeyati M, Grossman L, Kraemer KH, Wei Q (2002) Rapid assessment of repair of ultraviolet DNA damage with a modified host-cell reactivation assay using a luciferase reporter gene and correlation with polymorphisms of DNA repair genes in normal human lymphocytes. Mutat Res 509: 165-174

Sanyal S, Festa F, Sakano S, Zhang Z, Steineck G, Norming U, Wijkstrom H, Larsson P, Kumar R, Hemminki K (2004) Polymorphisms in DNA repair and metabolic genes in bladder cancer. Carcinogenesis 25: $729-734$

Shen H, Sturgis EM, Khan SG, Qiao Y, Shahlavi T, Eicher SA, Xu Y, Wang X, Strom SS, Spitz MR, Kraemer KH, Wei Q (2001) An intronic poly (AT) polymorphism of the DNA repair gene XPC and risk of squamous cell carcinoma of the head and neck: a case-control study. Cancer Res 61: $3321-3325$

Wacholder S, Chanock S, Garcia-Closas M, El ghormli L, Rothman N (2004) Assessing the probability that a positive report is false: an approach for molecular epidemiology studies. J Natl Cancer Inst 96: $434-442$

Zeegers MP, Tan FE, Dorant E, van Den Brandt PA (2000) The impact of characteristics of cigarette smoking on urinary tract cancer risk: a metaanalysis of epidemiologic studies. Cancer 89: 630-639 